\title{
The case against protecting the environment from ionising radiation
}

\author{
J.T. S mith \\ Centre for Ecology and Hydrology, DT2 8ZD Winfrith Technology Centre, Dorchester, UK
}

\begin{abstract}
The objective of this paper is to present the (rarely heard) argument in favour of retention of the present system of radiation protection of the environment. There has been a recent trend in the radioecological and radiation protection community towards greater regulation of the effects of ionising radiations on biota. In particular, the often quoted International Commission on Radiation Protection (ICRP) hypothesis that: If humans are protected from the effects of ionising radiation, then flora and fauna are also adequately protected has been criticised as being too anthropocentric and not adequate for protection of the environment. In this paper I will challenge this view, arguing firstly that this statement is almost always quoted out of its proper context, and secondly that the ICRP hypothesis does adequately protect the environment from the effects of ionising radiations. In view of the relatively insignificant effect of regulated releases of ionising radiation on the environment, the economic cost of further regulation will not result in a significant environmental benefit. Whilst empirical research to test the ICRP hypothesis should continue, until there is clear evidence against it, this simple and cost-effective approach should be retained. This would benefit the environment by directing scarce resources to more urgent environmental problems.
\end{abstract}

\section{INTRODUCTION}

In recent years a new fashion for the protection of the environment against the effects of radiation has emerged within the radioecological and radiation protection community. The arguments concerning this issue are varied [1]. Firstly, the statement of the ICRP [2] that

if man is adequately protected [from ionising radiation] then other living things are also likely to be sufficiently protected

has been criticised as "anthropocentric" and inadequate for protection of the environment from ionising radiation. This statement, usually quoted out of context, appears dismissive of the important issue of environmental protection. It is worth, therefore, reading the full paragraph in which this statement appears, as quoted in [3]:

Although the principal objective of radiation protection is the achievement and maintenance of appropriately safe conditions for activities involving human exposure, the level of safety required for the protection of all human individuals is thought likely to be adequate to protect other species, although not necessarily individual members of these species. The Commission therefore believes that if man is adequately protected then other living things are also likely to be sufficiently protected. 
Though much criticised in recent years, this statement has the considerable virtue of being a scientific hypothesis. In contrast to many statements made on this issue, the wording is clear and the words used can be defined in a scientifically meaningful way. It is therefore falsifiable, fulfilling the key criterion of a scientific hypothesis [4]. It is not an "anthropocentric" approach. It uses humans as the most radio-sensitive "sentinel" species in order to protect all other species. As I will discuss below, this hypothesis has been tested by a wealth of empirical observations and has thus far protected the environment against damage from ionising radiation. It is, however, fair to criticise the statement because it only presents the hypothesis without reference to the vast body of empirical data supporting it.

It has been argued that this current system of environmental protection is inadequate for a number of reasons, including perceived "data gaps", the presence of habitats where wildlife is exposed, but humans are not, and that the system for radiation protection needs to be harmonised with systems for chemical pollutants. In this paper I will argue that these criticisms are not valid. Whilst the ICRP statement [2] may need updating, this simple hypothesis has not been falsified. In view of the insignificant effect of regulated releases of ionising radiation on wildlife, I believe that the simple and cost effective regulatory approach should be retained. This would allow more resources and regulatory effort to go to the many more pressing environmental problems we face.

\subsection{Context}

The damage humans have done (and continue to do) to the environment is so obvious that it seems unnecessary to re-state it here. But it is important to consider regulatory efforts within the framework of overall environmental damage. Humankind's current rate of environmental destruction is staggering. Approximately 10.2 Million hectares (an area approximately the size of Greece) of forest are lost worldwide each year. A number of studies in recent years support the hypothesis that, because of human impacts such as this, "the biological world is approaching the sixth major extinction in history" [5]. Though the eventual consequences of increasing atmospheric carbon dioxide are not known with certainty, the scientific consensus is that global warming could be catastrophic to humankind and ecosystems. In view of this ongoing environmental crisis, any sensible regulatory system should focus costs and resources on the most serious environmental problems and make regulation of minor or insignificant problems as simple as possible.

It is worth also considering more local environmental impacts, which are allowed within the frame of current environmental legislation. In doing this I intend to counter some of the current thinking on radiation protection of the environment which appears to assume that no level of damage to individual organisms by ionising radiation is tolerable: i.e. that the regulatory limit should be set on a "no observable effects" basis. Current regulation of environmental damage does not attempt to reduce that damage to zero: this would be impossible. It rather attempts to weigh benefits from an action against risks in a manner, which is acceptable to the public. Some examples of environmental impacts which are tolerated because they lead to a benefit to some or all of the human population are:

- Destruction of the bed of the Irish Sea by bottom trawling by commercial fisheries;

- Use of rotenone poison to protect salmon fisheries in Norwegian rivers. Rotenone not only kills salmon and their parasites, but also kills most other aquatic animals;

- Management of heather moorland by regular burning to provide habitat for game birds;

- Cultivation of land for bioenergy crops.

I do not here make any ethical judgement on these activities: I simply wish to make the point that many activities which damage or alter the ecosystem are allowed because of their perceived benefits. Though I do not believe that regulated radioactive releases do any significant damage to the ecosystem, I think that a "no observable effects" approach to their regulation would not necessarily be appropriate. 


\section{DISCUSSION}

\subsection{Environmental concentrations of anthropogenic radionuclides}

In assessing the regulatory requirements for environmental protection against radiation, it is useful to consider how serious an environmental problem this is. Clearly, if regulated releases were (or were likely to become) significantly damaging to the environment, then improved regulation would be urgently needed. The simplest approach to assessing the impact of radioactive pollution of the environment is to calculate concentrations of radionuclides, which could lead to a potentially significant dose. The simplest and most conservative method of estimating such concentrations is to calculate the minimum concentration of a radionuclide in any environmental object (soil, sediment, water, organism, or a tissue), which would lead to a defined maximum acceptable dose rate. I will here assume that the maximum allowable dose rate to any organism is $1 \mathrm{mGy} \mathrm{d}^{-1}$, as recommended by [6]. This compares with typical limits of $0.1-1.0 \mathrm{mSv} \mathrm{y}^{-1}$ for protection of the human population. For $\beta$ - and $\gamma$-radiation the limit to protect humans is therefore approximately one thousand times lower than that to protect biota. Note that FASSET [7] found "few indications of readily observable effects [on biota] at dose rates less than $100 \mu \mathrm{Gy} \mathrm{h}^{-1}\left[2.4 \mathrm{mGy} \mathrm{d}^{-1}\right]$ ".

In an infinitely extended medium uniformly contaminated by a radionuclide, the average energy deposited (per unit mass or volume) at any point in that medium is equal to the average energy generated at any point (per unit mass or volume). Therefore, a conservative estimate of the radionuclide activity concentration in an environmental medium required to give a dose rate $1 \mathrm{mGy} \mathrm{d}^{-1}$ can be calculated from the average energy generated per disintegration of the radionuclide. This approach is similar to that taken by Amiro [8].

Table 1. Minimum concentration, $C_{\min }$, of $\alpha$-emitting radionuclides in an organism or tissue ${ }^{*}$ which could result in a dose rate of $1 \mathrm{mGy} \mathrm{d}^{-1}$.

\begin{tabular}{lccc}
\hline Radionuclide & $\begin{array}{c}\text { Mean } \Sigma \varepsilon \text { per } \\
\text { disintegration, MeV }\end{array}$ & $\begin{array}{c}\text { Dose rate, } \mathrm{mGy} \mathrm{d}^{-1} \\
\text { per Bq kg-1 }\end{array}$ & $\begin{array}{c}\text { Minimum } \\
\text { concentration, Bq kg }{ }^{-1}\end{array}$ \\
\hline $\mathrm{Pu}-238$ & 5.48 & $7.6 \times 10^{-5}$ & 13,200 \\
$\mathrm{Pu}-239$ & 5.14 & $7.1 \times 10^{-5}$ & 14,100 \\
$\mathrm{Pu}-240$ & 5.12 & $7.1 \times 10^{-5}$ & 14,000 \\
$\mathrm{Am}-241$ & 5.45 & $7.5 \times 10^{-5}$ & 13,300 \\
\hline
\end{tabular}

* It is appropriate, for $\alpha$-emitting radionuclides to consider internal doses only so these values are not here intended to apply to environmental media (soil, sediment, water).

Table 2. Minimum concentration, $C_{\min }$, of $\beta$ and $\gamma$-emitting radionuclides in an organism, tissue or environmental medium, which could result in a dose rate of $1 \mathrm{mGy} \mathrm{d}^{-1}$.

\begin{tabular}{lccc}
\hline Radionuclide & $\begin{array}{c}\text { Mean } \Sigma \varepsilon \text { per } \\
\text { disintegration, } \\
\text { MeV }\end{array}$ & $\begin{array}{c}\text { Dose rate, mGy d } \\
\text { per Bq kg }\end{array}$ & $\begin{array}{c}\text { Minimum } \\
\text { concentration, Bq kg }{ }^{-1}\end{array}$ \\
\hline H-3 & 0.0059 & $8.17 \times 10^{-8}$ & 12300000 \\
C-14 & 0.051 & $7.05 \times 10^{-7}$ & 1420000 \\
P-32 & 0.696 & $9.6 \times 10^{-6}$ & 104000 \\
Co-60 & 2.60 & $3.59 \times 10^{-5}$ & 27900 \\
Sr-90/Y-90 & 1.13 & $1.56 \times 10^{-5}$ & 64000 \\
Tc-99 & 0.085 & $1.2 \times 10^{-6}$ & 854000 \\
I-131 & 0.55 & $7.6 \times 10^{-6}$ & 131500 \\
Cs-134 & 1.47 & $2.0 \times 10^{-5}$ & 49000 \\
Cs-137/ ${ }^{\mathrm{m}}$ Ba-137 & 0.81 & $1.12 \times 10^{-5}$ & 90000 \\
\hline
\end{tabular}


Values of $C_{\min }$ are given in Table 1 for some (primarily) $\alpha$-emitting radionuclides and in Table 2, for some $\beta$ and $\gamma$-emitting radionuclides. These values represent the minimum concentration in any object in a contaminated environment, which could give rise to a dose at the chosen threshold of $1 \mathrm{mGy} \mathrm{d}^{-1}$. In other words, if organisms (for $\alpha, \beta, \gamma$ ) soil, sediments, and water (for $\beta, \gamma$ ) contain radionuclide concentrations lower than this value then no organism can receive a dose of $1 \mathrm{mGy} \mathrm{d}^{-1}$ or greater from external and/or internal radiation. These therefore represent the lowest-level screening concentrations for effects of radiation on biota and will under-estimate activity concentrations required for a $1 \mathrm{mGy} \mathrm{d}^{-1}$ dose, particularly for $\gamma$-emitters.

It is worth noting that the concentrations presented in Tables $1 \& 2$ are, in the context of regulated radionuclide releases, extremely high. In the UK, for example, activity concentrations of anthropogenic radionuclides in the environment from regulated releases are typically a few Bequerels per $\mathrm{kg}$ or less [9]. I would be interested to know if there is anywhere in Western Europe where radionuclides from current regulated releases reach anywhere near these levels (excluding the coastal area near Sellafield, UK, which is discussed below). The concentrations of alpha-emitting radionuclides presented in Table 1 are approximately one order of magnitude higher than those typically observed in the most contaminated few square kilometres of the Chernobyl Exclusion Zone or in the sediments of the Cooling Pond. Levels of ${ }^{137} \mathrm{Cs}$ and ${ }^{90} \mathrm{Sr}$ in soils in the most contaminated parts of the Exclusion Zone, however, can exceed the $C_{\min }$ values in Table 2 by one order of magnitude or more.

\section{2 "Data gaps"}

When considering the question of whether there are significant gaps in the data available to assess environmental impacts of radiation in biota, it is important to remember that there are always an infinite number of "data gaps" in any regulatory system. It is obviously impossible to collect information on radionuclide uptake to every tissue of every species of organism and to assess every effect on every species or combination of species. This truism lies behind proposals to regulate doses to biota using "reference species" [7, 10]. The question, then, is not "Are there data gaps?", because there are always data gaps, but "Is it worth spending money and effort to improve the data (and models) available?" Since there is never a point at which data is complete, this is a matter of judgement of where to focus resources to best protect the environment. For example, should taxpayers' money be spent on improving the system of radiation protection of biota, or should it be spent on attempting to prevent illegal logging of forests in developing countries? For reasons outlined here, I do not believe that damage to the environment from regulated releases of radioactivity is at all significant, so as a taxpayer concerned about the state of the environment I would choose the latter without hesitation.

A question related to "data gaps" concerns comparison between the system of radiation protection of biota and that of protection from chemical pollutants. I believe that there is more and better information available concerning the environmental transfers and effects of radioactivity on biota than on most chemical (particularly organic) contaminants. For example, there is little or no information on uptake and effects of many organic pollutants in predatory birds, partly because experimentation on such species is ethically unacceptable to many people. Data from rats or domestic birds are commonly used instead in hazard assessments (e.g. [11]).

\subsection{Testing the ICRP hypothesis at Savannah River and Sellafield}

Whicker and Bedford [3] examined the ICRP hypothesis in relation to radiation doses arising from radioactivity in Par Pond, a former reactor cooling reservoir at the Savannah River site in the USA. The partially drained pond was contaminated with around $1 \mathrm{MBq} \mathrm{m}{ }^{-2}$ of ${ }^{137} \mathrm{Cs}$. This study [3] concluded that "Whereas the potential maximum lifetime risk of fatal cancer for humans was about $3 \times 10^{-3}$ (over one order of magnitude above that requiring action under the US Environmental Protection Agency's "Superfund" Act), the risk to local biota was two to three orders of magnitude below the threshold for reproductive impairment." The Savannah River site did have a detrimental effect on the ecology of some local aquatic systems, but this was due to the release of cooling water at a temperature of around $80^{\circ} \mathrm{C}$, not to radioactive releases. 
Releases of radioactivity from the Windscale/Sellafield site in the UK provide another test of the ICRP hypothesis. Discharges of radioactivity from Sellafield to the Irish Sea resulted in exposures, during the 1970 's, to a critical group of local people (with high consumption rates of locally caught fish, crustaceans and molluscs) of approximately $2-3 \mathrm{mSv} \mathrm{y}^{-1}$ [12]. This is significantly higher than current guidelines for doses to members of the public arising from nuclear installations (in the UK these should be limited to $<0.3 \mathrm{mSv} \mathrm{y}^{-1}$ ). In spite of the relatively high doses to the human population, biota were not affected by releases from Sellafield. Kershaw et al. [12] quote Woodhead (1980):

The dose rates around Sellafield are at least an order of magnitude below those which would be expected to elicit any effect under controlled laboratory conditions, and about two orders of magnitude below those which might be expected to have an effect at the population level (Woodhead, 1980) during the period of maximum discharges.

\subsection{Accidentally contaminated environments}

It has been argued that the ICRP hypothesis is limited because it does not apply to areas such as the Chernobyl Exclusion Zone where humans are not exposed to ionising radiation but organisms are. This argument does not, however, invalidate the ICRP hypothesis. Firstly, the Chernobyl accident, obviously, was not a regulated release. Secondly (and again obviously), radiation dose rates to people in the Chernobyl zone exceeded limits by several orders of magnitude so the ICRP hypothesis would prohibit a release of this size. The hypothesis that if man is adequately protected [from ionising radiation] then other living things are also likely to be sufficiently protected is not invalidated.

Studies of the area around Chernobyl appear to support the ICRP hypothesis rather than contradict it. It is well known (e.g. [13]) that extremely high dose rates during and shortly after the accident led to serious damage to wildlife (to pine trees in particular) in some areas. There is evidence (though some is contradictory) that much lower chronic exposures in subsequent years have had a detrimental effect on organisms [14-15]. A recent study [16] of small mammals in the "Red Forest" found no evidence of physiological effects of radiation.

In assessing the ecological consequences of the Chernobyl accident, the (potential) negative impact of radiation on the environment must be weighed against the positive impact the removal of humans from the area has had on wildlife habitats. On a macro-ecological (i.e. large-) scale, there has been a dramatic increase in populations of wild mammals and bird species [17]. Radiation levels in the $30 \mathrm{~km}$ Zone are still in many areas much higher than those considered safe for human habitation. But wildlife appears to have been relatively unaffected by the radiation and has therefore benefited from the absence of human disturbance and damage through agriculture, forestry, hunting and fishing. I do not wish in any way to downplay the tragic consequences of Chernobyl to the human population of the area. However, the experience from Chernobyl is a clear demonstration of the insignificance of radiation effects on wildlife compared to the huge impact of humankind's everyday activities.

\subsection{Deep sea waste disposal}

The deep sea is one wildlife habitat not utilised by humans and therefore the ICRP hypothesis may not apply. Past dumping of waste in the deep North Atlantic could have led to doses to marine organisms of up to $\sim 0.2 \mathrm{mGy} \mathrm{d}^{-1}$ [18] whilst exposures to humans were minimal. Deep sea disposal may therefore require specific assessment of doses to biota. This issue may, however, be somewhat academic in Western Europe since the OSPAR convention (OSPAR: Commission for the protection of the marine environment of the North East Atlantic) prohibits dumping of waste at sea. 


\section{CONCLUSIONS}

\subsection{Public perception and "political" considerations}

It would be naïve to think that the current focus on protecting the environment from ionising radiation is based on a genuine belief that this will prevent environmental damage. I know of no incidents of regulated releases of radioactivity in Western Europe, which have caused any radiation damage to wildlife. As discussed above, there are bigger environmental problems to be addressed. The intention therefore appears to be to develop a system of environmental protection, which is more palatable to pressure groups, politicians and the public than the somewhat stark ICRP hypothesis. This is a worthwhile goal, but I do not believe that the approach currently proposed $[1,7,10]$ is either the most efficient or effective.

\subsection{A pragmatic approach}

I believe that whilst empirical research to test the ICRP hypothesis should continue, this simple and cost-effective approach should be retained until there is clear evidence to show that it does not work. The statement could be re-written to better demonstrate that this is not simply an "anthropocentric" approach and to better highlight the wealth of empirical evidence to support it. Many people perceive environmental regulations to be too "political" and insufficiently focused on real environmental problems. I believe that a clear and simple response to this issue is the best way to alleviate people's natural concern over potential radiation damage to the environment. This would be a proportionate response to this insignificant problem. Furthermore, it would benefit the environment by directing scarce resources to more significant and urgent environmental problems.

\section{References}

[1] IUR, J. Environ. Radioactivity 70 (2003), 155-159.

[2] ICRP (1977) Recommendations of the ICRP, Publication 26, Pergamon Press, Oxford.

[3] Popper K. Conjectures and Refutations. (Routledge, London, 1963). 431 pp.

[4] Whicker, F.W. and Bedford, J.S., "Protection of the natural environment from ionizing radiation: are specific criteria needed?" In: Environmental Impact of Radionuclide Releases (IAEA, Vienna, 1995) pp. 561-567.

[5] Thomas J.A., Telfer M.G., Roy D.B., Preston C.D., Greenwood J.J.D., Asher J., Fox R., Clarke R.T. and Lawton J.H. Science 303 (2004), 1879-1881.

[6] IAEA Effects of ionising radiation on plants and animals at levels implied by current radiation standards. International Atomic Energy Agency Technical Reports No. 332 (IAEA, Vienna, 1992).

[7] FASSET. Final report. (Swedish Radiation Protection Authority, Stockholm, 2004) 111 pp.

[8] Amiro B.D., J. Environ. Radioactivity 35 (1997), 37-51.

[9] RIFE. Radioactivity in food and the environment, 2002. (EA, Warrington, 2003) 213 pp.

[10] Pentreath R.J., J. Environ.l Radioactivity 74 (2004), 19-30.

[11] EC. EU Risk assessment report: Bis(pentabromophenyl) ether. Vol. 17, EUR 20402EN (European Commission, Luxembourg, 2002), 282 pp.

[12] Kershaw P.J., Pentreath R.J., Woodhead D.S. and Hunt G.J. A review of radioactivity in the Irish Sea. MAFF Aquatic Environment Monitoring Report, 32 (MAFF, Lowestoft, 1992) 65 pp.

[13] IAEA The International Chernobyl Project Technical Report (International Atomic Energy Agency, Vienna, 1991) 640 pp.

[14] Kovalchuk, I., Dubrova, Y.E., Arkhipov, A., Hohn, B. and Kovalchuk, I. Nature 407 (2000) 583-584.

[15] Sugg D.W., Bickham J.W., Brooks J.A., Lomakin M.D., Jagoe C.H., Dallas C.E., Smith M.H., Baker R.J. and R.K. Chesser, R.K., Environ. Toxicol. Chem. 15 (1996), 1057-1063.

[16] Jackson, D., Copplestone, D. and Stone, D.M. In press (2004).

[17] Williams N., Science 269 (1995) p. 304.

[18] Woodhead D.S. "Dosimetry and the assessment of environmental effects of radiation exposure" In Radioecology after Chernobyl, F.E. Warner and R.M. Harrison Eds. (Wiley \& Sons, Chichester, 1993) pp. 291-306. 